\title{
Biosafety assessment of pig manure during composting with straw, sawdust and greenwaste bulking agents
}

\author{
G Mc Carthy ${ }^{1}$, P G Lawlor ${ }^{2}$, T Nolan², M Gutierrez ${ }^{3}$, G E Gardiner ${ }^{1}$
}

${ }^{1}$ Chemical and Life Science Department, Waterford Institute of Technology, Co. Waterford, Ireland, ${ }^{2}$ Teagasc, Pig Production Development Unit, Moorepark, Fermoy, Co. Cork, Ireland, ${ }^{3}$ Central Veterinary Research Laboratory, Department of Agriculture, Fisheries and Food, Backweston Campus, Celbridge, Co. Kildare, Ireland

Email: gmccarthy@wit.ie

Introduction Utilising pig manure as a sustainable resource for solid biofuel manufacture could potentially assist the pig industry in complying with the Nitrates Directive Action plan introduced by SI No. 378 (2006) which has imposed restrictions on land spreading of pig manure. However, a pig manure-derived solid biofuel may pose a biosafety risk to end-users, as any pathogens present in the manure may be carried over to the end product. Furthermore, in order to place a processed manure product on the market, it must comply with microbiological standards as set out in EU regulation EC/1774/2002 (amended by EC/208/2006). Therefore, strategies are required to reduce the disease risk of manure if it is to be converted into a marketable solid biofuel. The aim of this study was to investigate if composting is effective in eliminating and/or reducing pathogenic and indicator micro-organisms.

Materials and methods Manure from the pig unit at Teagasc Moorepark was mechanically separated into solid and liquid fractions using a decanter centrifuge. The solid component was composted alone (control) or mixed with the following bulking agents in a ratio of $\sim 2: 1$; sawdust, greenwaste (a mixture of tree leaves, foliage and small twigs), or straw. Composting was performed in insulated compost tumblers and each of the four treatments was replicated three times. The temperature of the compost was recorded daily. Microbiological analyses were performed on the unseparated manure, manure solids and the bulking agents and on compost samples at days 0, 7, 14, 21 and 56 as follows; samples were homogenised in buffered peptone water as 1:10 dilutions and serially diluted 10-fold in maximum recovery diluent. Appropriate dilutions were pour-plated on selective media to enumerate coliform, E. coli, Enterococcus and yeasts and moulds. To enumerate aerobic spore-forming bacteria $1: 10$ dilutions were heated to $80{ }^{\circ} \mathrm{C}$ for 10 min prior to plating. In addition, the presence/absence of Salmonella was determined in 25g samples (ISO6579:2002 Annex D). Any Salmonella isolates recovered were serotyped according to the Kauffman-White scheme and assayed for susceptibility to a panel of 14 antimicrobials using a broth dilution method. Data were log-transformed prior to analysis for repeated measures using the PROC MIXED procedure of SAS. Linear and quadratic polynomial contrasts were performed on all analyses to determine the effect of composting on microbial counts over time.

Results Salmonella Livingstone was detected in the sawdust prior to composting. The strain recovered was fully sensitive to all of the antibiotics tested. Salmonella was not detected in the two other bulking agents, the manure, manure solids or in any of the compost treatments at any timepoint. Table 1 shows the change in microbial counts over time across all treatments during the 56-day composting period. A quadratic response was observed for E. coli counts $(\mathrm{P}<0.001)$, Enterococcus counts $(\mathrm{P}<0.001)$ and yeast and mould counts $(\mathrm{P}<0.001)$. Changes in counts of coliform and aerobic sporeforming bacteria were observed on different sampling days $(\mathrm{P}<0.001)$. Tendencies towards a quadratic response over time were observed for both coliform $(\mathrm{P}=0.10)$ and aerobic spore-forming bacteria $(\mathrm{P}=0.07)$. Mean microbial counts were not influenced by treatment $(\mathrm{P}>0.05)$.

Table 1 Effect of sampling day on mean microbial counts $\left(\log _{10} \mathrm{CFU} / \mathrm{g}\right)$ in pig manure-derived compost

\begin{tabular}{|c|c|c|c|c|c|c|c|c|c|}
\hline & \multicolumn{5}{|c|}{ Day } & \multirow[b]{2}{*}{ SE } & \multicolumn{3}{|c|}{ P-value } \\
\hline & 0 & 7 & 14 & 21 & 56 & & Overall & Linear & Quadratic \\
\hline E. coli & 5.33 & 2.00 & 2.00 & 2.00 & 2.00 & 0.049 & $<0.001$ & $<0.001$ & $<0.001$ \\
\hline Coliform & 5.39 & 2.82 & 5.07 & 5.22 & 3.66 & 0.268 & $<0.001$ & 0.83 & 0.10 \\
\hline Enterococci & 4.89 & 2.03 & 2.04 & 2.05 & 2.00 & 0.044 & $<0.001$ & $<0.001$ & $<0.001$ \\
\hline Yeasts \& moulds & 5.41 & 3.12 & 3.80 & 4.09 & 4.68 & 0.141 & $<0.001$ & 0.61 & $<0.001$ \\
\hline Aerobic spore-formers & 5.59 & 5.56 & 5.80 & 5.41 & 5.86 & 0.079 & $<0.001$ & 0.31 & 0.07 \\
\hline
\end{tabular}

Conclusions By day 7, coliform, E. coli and Enterococcus counts had decreased in the compost, most likely because the temperature had increased to $59{ }^{\circ} \mathrm{C}$. Although coliform counts subsequently increased as the temperature decreased to 37 ${ }^{\circ} \mathrm{C}$, they had declined again by day 56 . The resulting compost complies with EU regulations, which state that a marketable processed manure product must be free from Salmonella, with E. coli or Enterococcus counts not exceeding $3.0 \log _{10} \mathrm{cfu} / \mathrm{g}$. However, regulations also state that the product 'must be subjected to a reduction in spore-forming bacteria' and although spore-former counts tended to be reduced during composting, final counts were higher than those on day 0 . Although yeasts and mould counts changed over time, the relatively high counts in the final product may be potentially hazardous due to the risk posed by exposure to spores. However, identification of moulds and spore-forming bacteria is required in order to determine the potential risks posed by either. Furthermore, processing of the manure-derived compost into a solid biofuel may reduce levels of these micro-organisms. It is worth noting that bulking agents should be selected carefully, as the sawdust contained Salmonella, albeit a serotype not commonly associated with human infection.

Acknowledgements This research was funded by the HEA Technological Sector Research Strand I Programme and the Department of Agriculture and Food's Research Stimulus Fund Programme under the National Development Plan 20072013

References ISO 6579:2002, Amendment 1, Annex D. Detection of Salmonella spp. in animal faeces and in samples of the primary production stage. 